Article

\title{
Isolation of CHS Gene from Brunfelsia acuminata Flowers and Its Regulation in Anthocyanin Biosysthesis
}

\author{
Min Li ${ }^{\dagger}$, Yu-Ting Cao ${ }^{\dagger}$, Si-Rui Ye, Muhammad Irshad, Teng-Fei Pan and Dong-Liang Qiu * \\ College of Horticulture, Fujian Agriculture and Forestry University, Fuzhou 350002, China; \\ liminzyl@sina.com (M.L.); caoyt87@163.com (Y.-T.C.); yesirui@163.com (S.-R.Y.); \\ irshadaup@gmail.com (M.I.); tfpan@fafu.edu.cn (T.-F.P.) \\ * Correspondence: qiudl1970@fafu.edu.cn; Tel.: +86-591-83789379 \\ + These authors contributed equally to this paper.
}

Academic Editor: Derek J. McPhee

Received: 17 November 2016; Accepted: 25 December 2016; Published: 29 December 2016

\begin{abstract}
Chalcone synthase gene $(\mathrm{BaCHS})$ from Brunfelsia acuminata flowers was isolated using RT-PCR and RACE. The coding region of the gene is $1425-\mathrm{bp}$ with an open reading frame of 1170-bp, 73-bp 5'UTR, and 172-bp 3'UTR. Its deduced protein does not have a signal peptide but does contain a cond_enzyme superfamily domain, and consists of 389 amino acids with a predicted molecular mass of $42,699 \mathrm{Da}$ and a pI of 6.57. The deduced amino acid sequence of BaCHS shares $90 \%, 88 \%$, $85 \%, 84 \%$ and $79 \%$ identity with CHS from Petunia hybrida, Nicotiana tabacum, Solanum lycopersicum, Capsicum annuum and Camellia sinensis, respectively. The striking color change from dark purple to light purple and ultimately lead to pure white resulted from a decline in anthocyanin content of the petals and was preceded by a decrease in the expression of $\mathrm{BaCHS}$. Its gene expression was positively correlated with the contents of anthocyanin $(p \leq 0.01)$.
\end{abstract}

Keywords: Brunfelsia acuminata; flower color; anthocyanin biosynthesis; chalcone synthase (CHS); RT-qPCR

\section{Introduction}

Flower color is one of the most important characteristics of floriculture plants. Flower color results from the accumulation of flavonoids, carotenoids or betalains, and the type of accumulated pigments largely relies on plant species. Chalcone synthase plays a significant role in flavonoid biosynthesis by catalyzing the stepwise condensation of 4-coumaroylcoenzyme A ( $\mathrm{CoA}$ ) produced from the phenylpropanoid pathway with three acetate units from malonyl-CoA and cyclizing the resulting tetraketide intermediate to naringenin chalcone, which is a flavonoid skeleton [1]. Since the first CHS gene was isolated from parsley [2,3], hundreds of CHS genes have been cloned from different plants such as Petunia hybrida [4], maize [5], Arabidopsis [6], Antirrhinum majus [7], Gerbera hybrid [8], Vitis vinifera [9] and Tulipa fosteriana [10]. CHS genes in Petunia hybrida compose a multigene family with twelve CHS genes, but only CHSA and CHSJ are expressed in flower corolla, tube and anthers [11,12]. The expression of $\mathrm{CHS}$ gene could alter flower pigmentation by transferring antisense chalcone synthase cDNA to Gerbera hybrid [13].

Anthocyanins are a type of flavonoid compound responsible for the pink, orange, red, scarlet, purple, blue and cyanic flower colorationx in many plant species. They are widely distributed in higher plants and their structure and biosynthesis have been well studied [14,15].

In addition to cloning and sequence analysis of the chalcone isomerase gene $(\mathrm{CHI})$ from Brunfelsia acuminata flowers [16], anthocyanin degradation in plants was studied in flowers of Brunfelsia calicina (Solanaceae) $[17,18]$. These flowers change color from dark purple to pure white 
within the first 2 days of opening. The process is dependent on anthocyanin degradation and de novo synthesis of mRNAs and proteins of peroxidase (BcPrx01) [17,18]. However, to our knowledge, little is known about the CHS gene from Brunfelsia acuminata flowers and its role in anthocyanin biosynthesis. Therefore, the aim of this study was to isolate the full-length cDNA of the CHS from Brunfelsia acuminata flowers and analyze the sequences and expression of the cDNA. A better understanding of the mechanism of transcriptional regulation of the Brunfelsia acuminata CHS gene may advance genetic engineering of the flower color.

\section{Results}

A particularly interesting feature of Brunfelsia acuminata petals is their striking color change from dark purple to light purple and ultimately to pure white as petal coloration develops. These colors changes are associated with a decline in anthocyanin content of the petals. Anthocyanin accumulated to a maximum level at Day 0 and degraded to a minimum level at day 5 (Figure 1).

To identify the major regulatory genes affecting anthocyanin accumulation in Brunfelsia acuminata petals, the expression patterns of anthocyanin biosynthetic genes were studied using RT-PCR. The full-length sequence of the CHS gene sequence was isolated using a combination of RT-PCR and RACE-PCR. The result demonstrated that the full-length cDNA was assembled as a 1415-bp sequence with a poly (A) tail, and contained an 1170-bp ORF encoding a 389 amino acid protein (Figure 2).
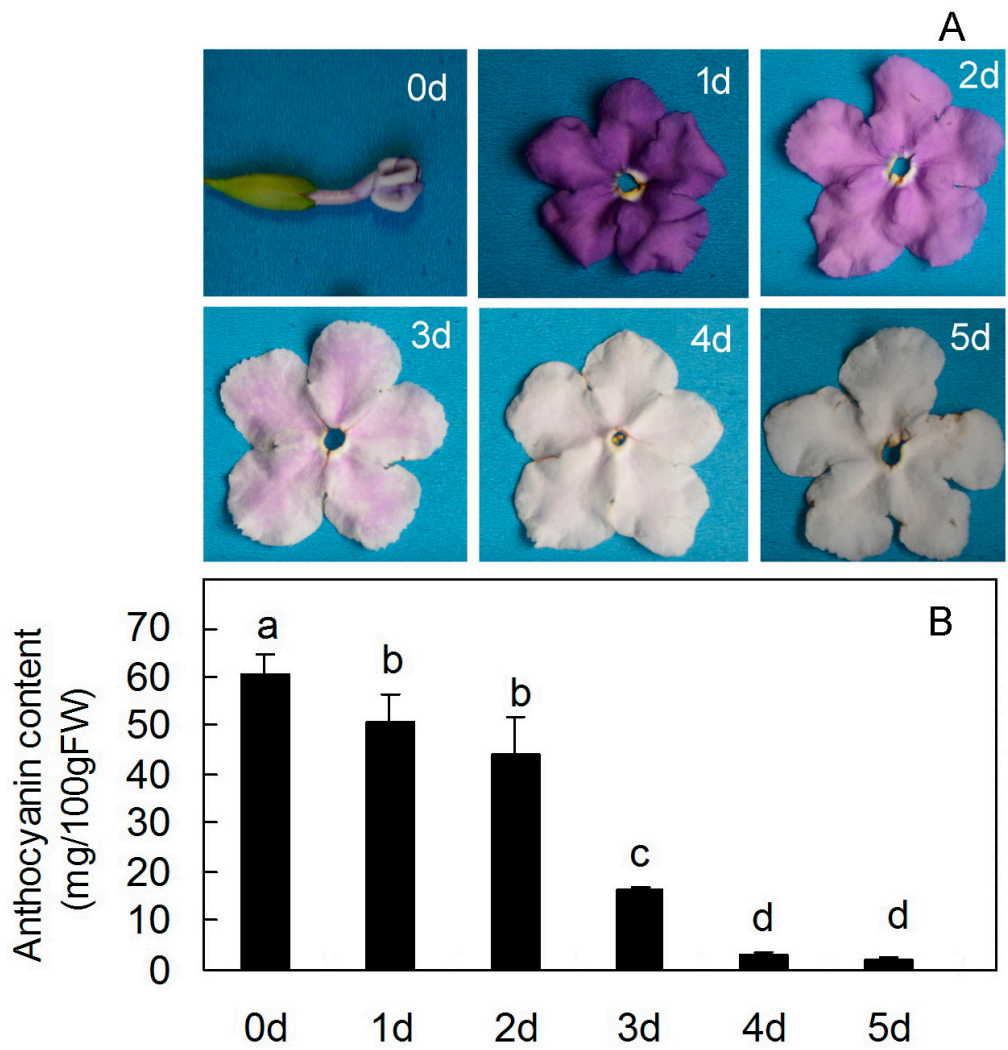

Figure 1. Change in anthocyanin content in petals at sequential stages of flower opening and senescence over 6 days. (A) Brunfelsia acuminata petals at sequential stages of flower opening and senescence over 6 days; (B) The anthocyanin content at sequential stages of flower opening and senescence over 6 days. The data represent means \pm SD of three replicate $(n=3)$. Where no error bars are present, The SD was smaller than the size of the symbol. Different letters indicate significant differences $(p<0.05)$. 

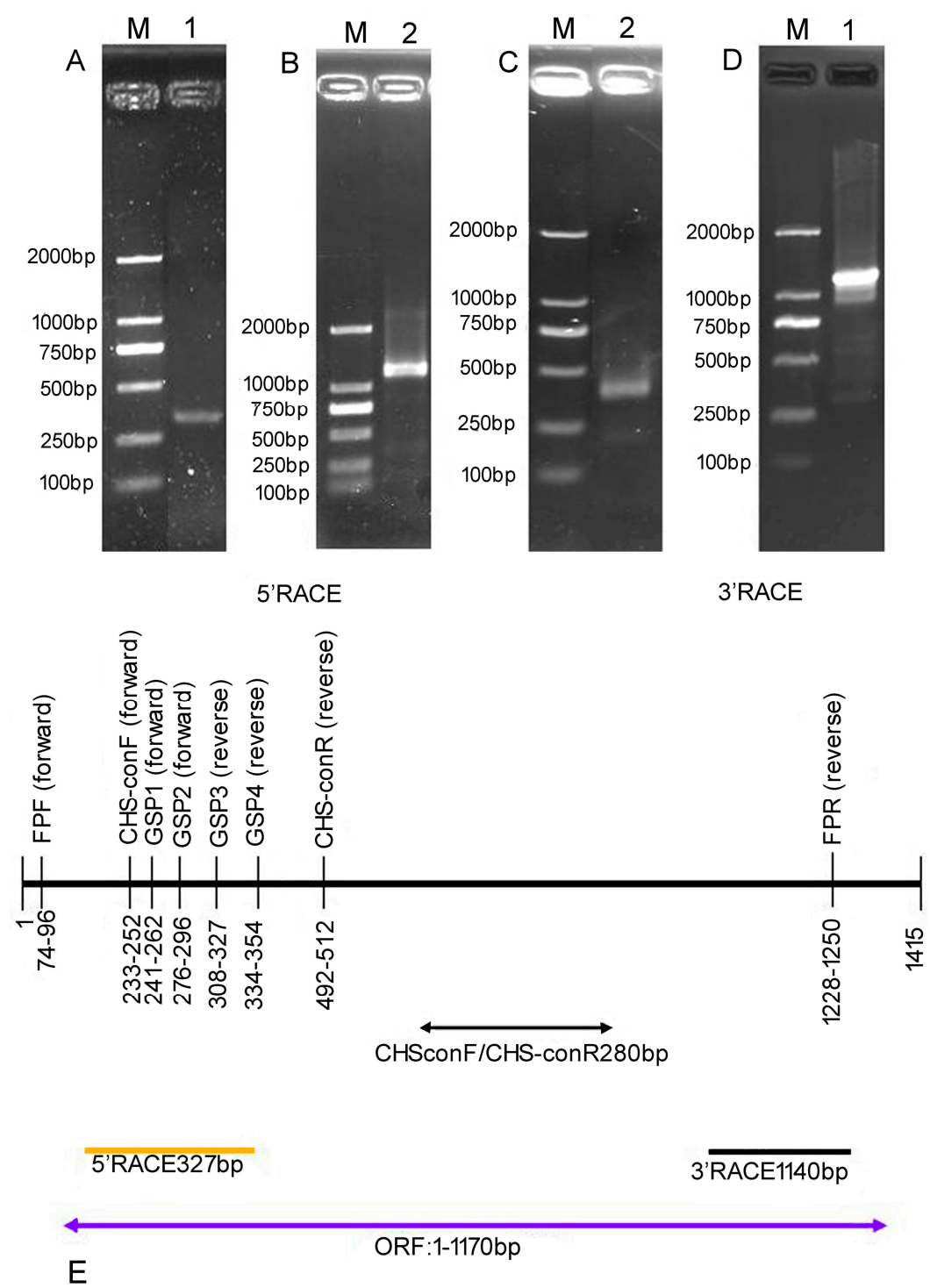

Figure 2. Isolation and identification of BaCHS. (A) RT-PCR products from the petals of Brunfelsia acuminata with primers CHS-ConF /CHS-ConR for lane 1. Marker: DL-2000 marker; (B) 3'RACE-PCR products from the petals of Brunfelsia acuminata with GSP1/ GSP2 3'RACE-PCR inner primer; (C) 5'RACE-PCR products from the petals of Brunfelsia acuminata with GSP3/GSP4 5'RACE-PCR inner primer; (D) The full cDNA products of Brunfelsia acuminata petals with FPF/FPR primers; (E) RT-PCR and RACE-PCR product lengths with different primers.

There was a $5^{\prime}$ untranslated region of 73-bp upstream from the start codon, and the coding region was followed by a $3^{\prime}$ untranslated region that was 173-bp downstream of the stop codon (Figure 3). Homology search revealed that the cDNA shared 90\% identities with CHS of Petunia hybrida (AF233638.1), 88\% identity to Nicotiana tabacum (AF311783.1), 85\% identities to Solanum lycopersicum (NM001247104.1), 84\% identity to Capsicum annuum (FJ705842.1), and 79\% identity to Camellia sinensis (AY169403.1). Therefore, this cDNA sequence was designated BaCHS with accession serial number JN966986 registered in GenBank. Alignment of protein sequences is shown in Figure 4. BaCHS shared higher sequence identity with the CHS proteins of Petunia hybrida (CAA32731.1), Rosa chinensis (AEC13058.1), Solenostemon scutellarioides (ABP57071.1), Catharanthus roseus (CAA10511.1), Rhododendron simsii (CAC88858.1), and Nelumbo nucifera (ADD74168.1). A high similarity among CHS proteins was observed from residues 40 to 389 . The deduced amino acid 
sequence of BaCHS was phylogenetically analyzed with CHSs from other plants. The phylogenetic tree grouped into several branches (Figure 5). BaCHS was most closely related to CHS from Petunia hybrida with higher bootstrap support and grouped into a small branch with CHS from Petunia hybrida. As expected, Brunfelsia acuminata was closely related to Solanaceae with high bootstrap. Brunfelsia acuminata, Petunia hybrida, Nicotiana tabacum, Solanum lycopersicum, Capsicum annuum, Nicotiana tabacum, Nicotiana alata, and Solanum tuberosum belong to the family Solanaceae and form one branch according to their higher identity of amino acid sequence throughout the entire coding region (Figure 4). Expression analysis of anthocyanin biosynthetic genes is shown in Figure 6. The transcript levels of $\mathrm{BaCHS}$ were higher during the bud (Day 0) and initial flowering (Day 1) stages than at later stages (Days 2-5). Anthocyannin accumulation was significantly correlated with the expression level of CHS gene. The expression of the genes appeared to suppress by Day 5 .

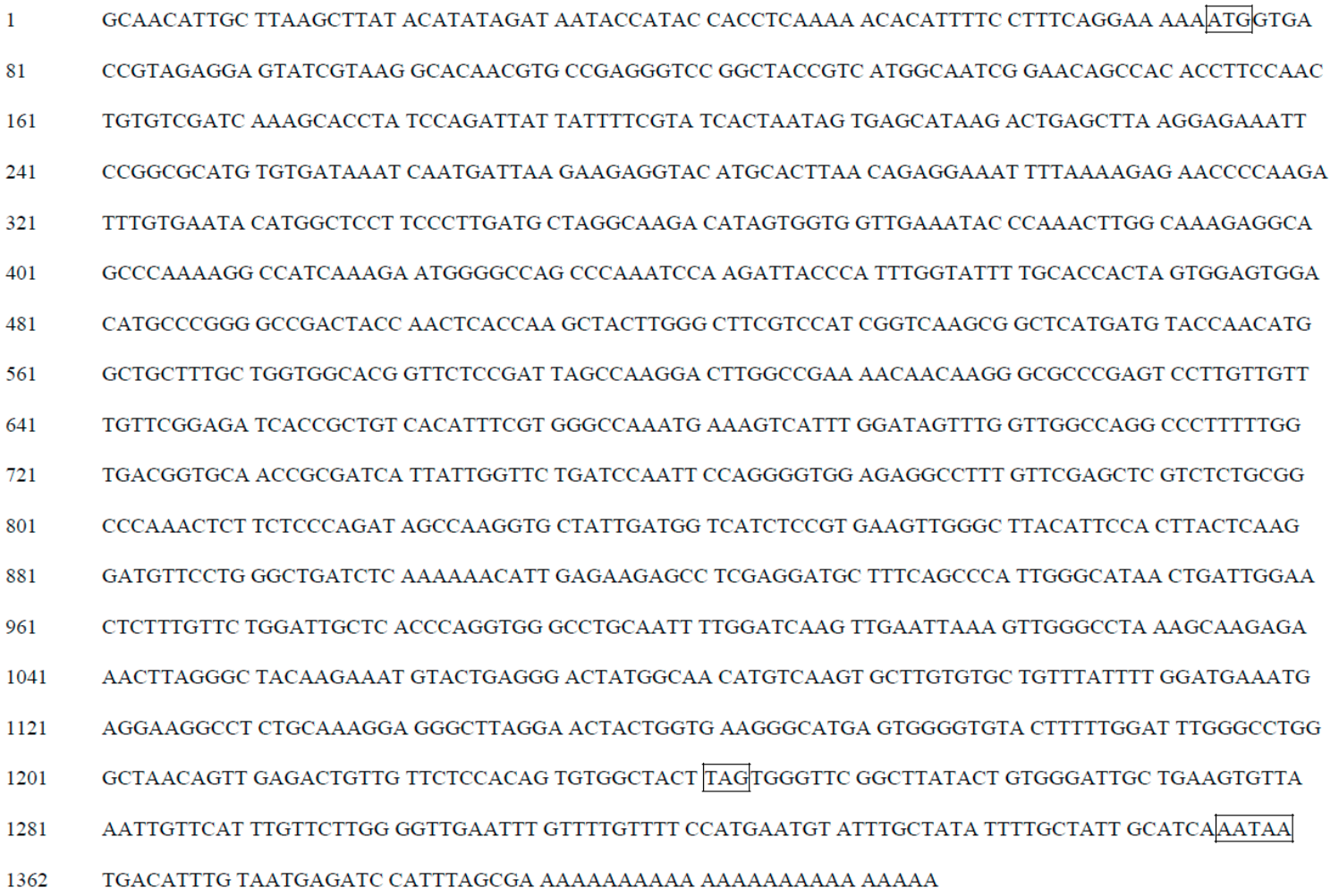

Figure 3. Full length of the sequence of CHS cDNA. ATG is start codon; TAG is stop codon; AATAA is the polyadenylation signal. The sequence contain $73 \mathrm{bp} 5^{\prime} \mathrm{UTR}$ and $173 \mathrm{bp} 3^{\prime} \mathrm{UTR}$, with a $1170 \mathrm{bp}$ open reading frame. The base the third left start codon, and the one following start codon is A and G respectively, which is obey the Kozak sequence.

Abundances were determined by comparison with an internal reference (BaActin). The data for raw measurement of BaActin mRNA expression is shown in Supplementary Materials. The anthocyanin accumulation in the new stem is minimum as compared to leave and flower (Figure 6). Total anthocyanin content was expressed from a weak to strong order thus: flowers $>$ leaves $>$ stems. 
Brunfelsia acuminata.seq Rosa chinensis.seq

Petuniaxhybrida.seq Catharanthus roscus.seq Rhododendron simsii.seq
Nelumbo nucifera.seq

Brunfelsia acuminata.seq Rosa chinensis.seq

Soluniaxhybrida.seg Catharanthus roscus.seq Rhododendron simsii.seq consensus

Brunfelsia acuminata.seq Rosa chinensis.seq

Solenostemon scutellarioides.sed Sous.seq Rhododendron simsii.seq consensus

Brunfelsia acuminata.seq Rosa chinensis.seq

Petuniaxhybrida.seq Solenostemon scutellario
Catharanthus roscus.seq Rhododendron simsii.seq Nelumbo nucifera.seq

Brunfelsia acuminata.seq Rosa chinensis.seq

Setuniaxhybrida.seq Catharanthus roscus.seq Rhododendron simsii.se consensus

Brunfelsia acuminata.seq Rosa chinensis.seg

Solenostemon scutellarioides.seq Catharanthus roscus.seq Rhododendron simsii.seq Relumbo nucifera.seq consensus

Brunfelsia acuminata.seq Rosa chinensis.seg

Solenostemon scutellarioides.seq oscus.seq Rhododendron simsii.seq consensus

Brunfelsia acuminata.seq Rosa chinensis.seq Solenostemon scutellarioides seq Catharanthus roscus.seq Rhododendron simsii.seq Nelumbo nucifera.seq consensus

Brunfelsia acuminata.seq Rosa chinensis.seq

Solenostemon scutellarioides.seq Catharanthus roscus.seq Rhododendron simsii.seq consensus

Brunfelsia acuminata.seq Rosa chinensis.seg

Solenostemon scutellarioides.seq Catharanthus roscus.seq Rhododendron simsii.seq consensus
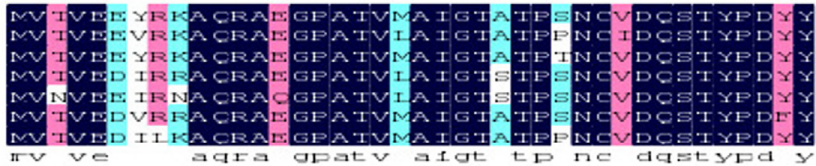

40
40
40
40
40
40
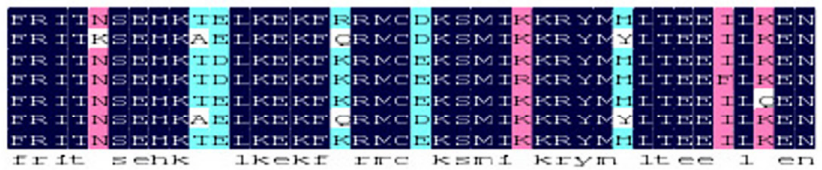

80
80
80
80
80
80
80
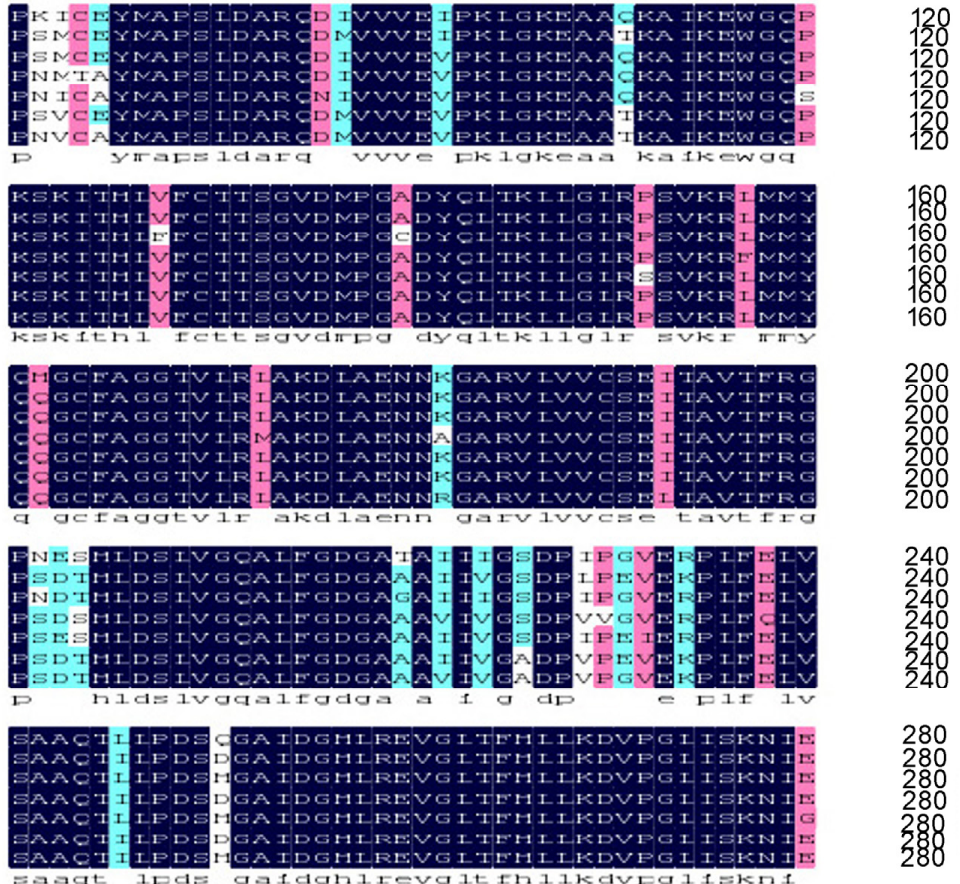

280
280
280
280
280
280
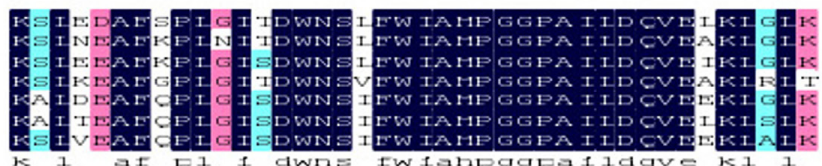

320
320
320
320
328
320

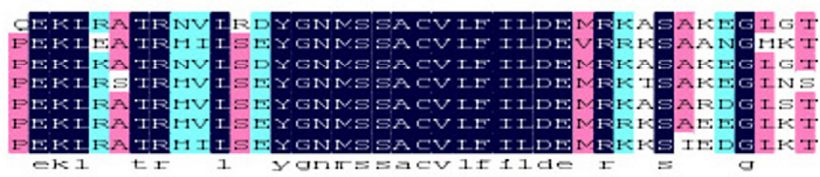

360
360
360
360
360
360
360

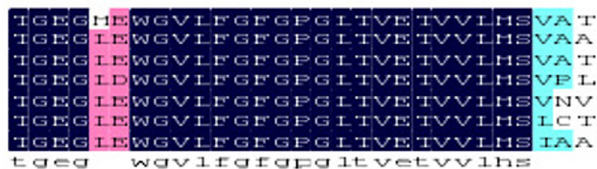

389
389
389
389
389
389
389

Figure 4. Multiple alignment of predicted amino acid sequences of CHS from different plants. Petunia hybrida, CAA32731.1; Rosa chinensis, AEC13058.1; Solenostemon scutellarioides, ABP57071.1; Catharanthus roseus, CAA10511.1; Rhododendron simsii, CAC88858.1; Nelumbo nucifera, ADD74168.1. 


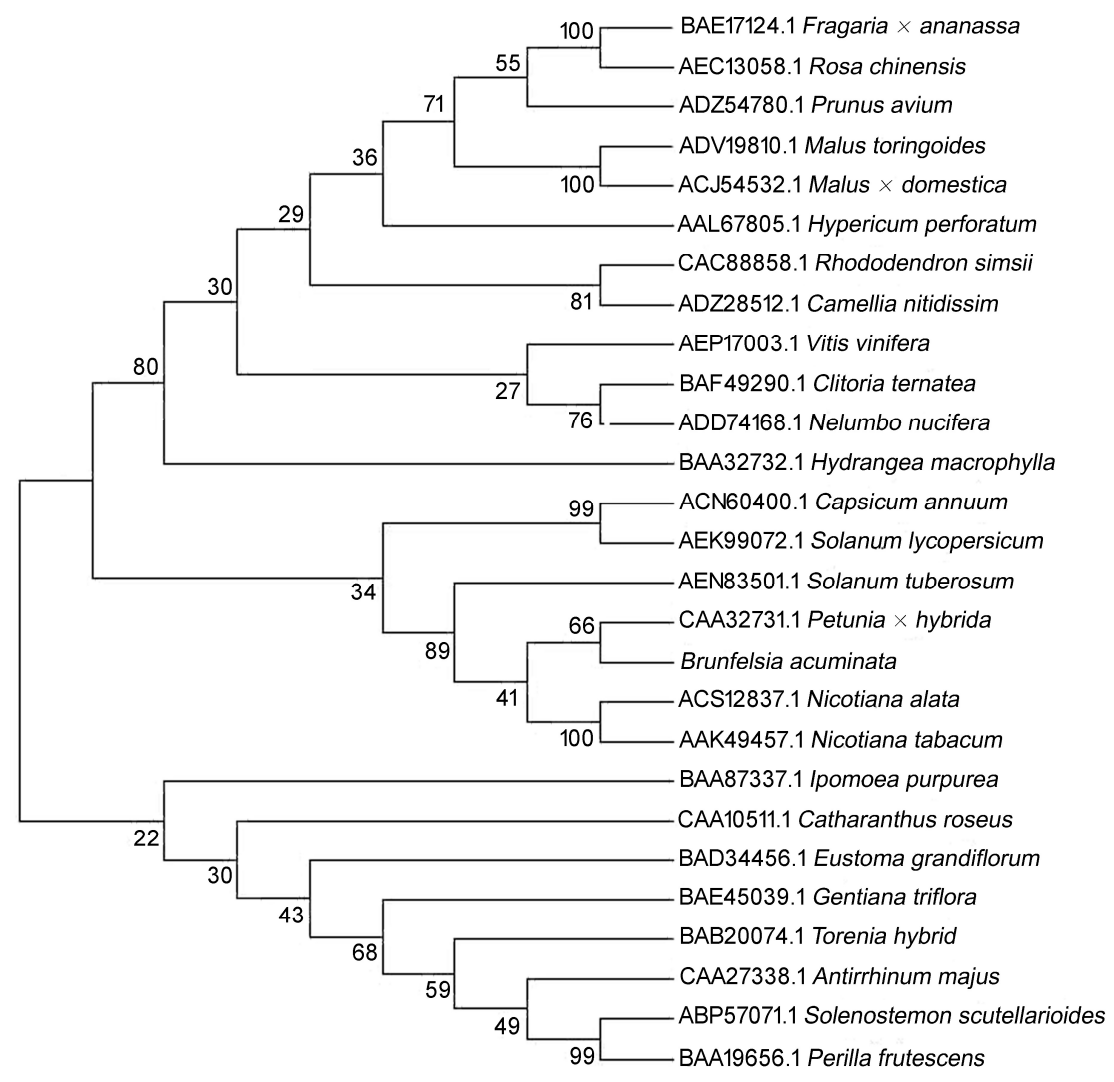

Figure 5. A Phylogenetic tree of deduced amino acid sequences of CHS constructed by software ClustalX 1.8 and MEGA 5.0 from Brunfelsia acuminata and from various other plant species. The phylogenetic tree is a neighbor-joining tree calculated by Poisson model, and the bootstrap values are from 1000 replications. The plants' names and their Genbank accession numbers are all shown in the figure.

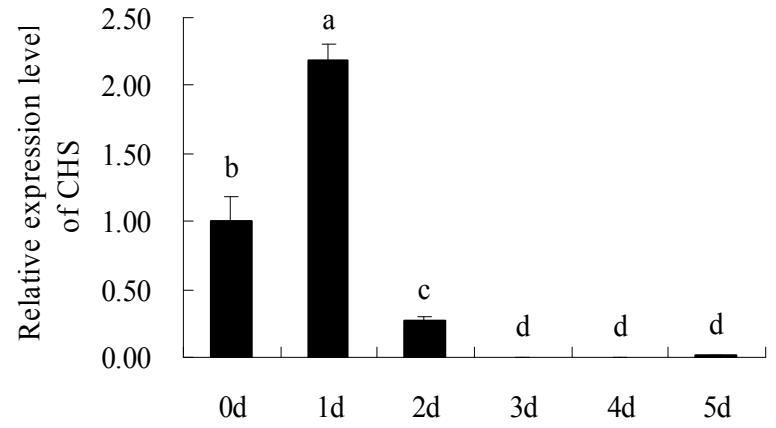

Figure 6. Expression patterns of $\mathrm{BaCHS}$ transcripts in the petals at sequential stages of flower opening over 6 days of Brunfelsia acuminata. Abundances were determined by comparison with an internal reference (BaActin) and are shown relative to the expression level on Day 0 , which was given a value of 1. The data represent means $\pm \mathrm{SD}$ of three replicate $(n=3)$. Where no error bars are present, The SD was smaller than the size of the symbol. Different letters indicate significant differences $(p<0.05)$.

\section{Discussion}

In this report, sequence analysis and comparison with $\mathrm{BaCHS}$ revealed that the ORF was $1170 \mathrm{bp}$ in length and putatively encoded a polypeptide of 389 amino acids, which had high similarities $(84 \%-90 \%)$ with CHSs from other plant species by blasting in NCBI. A putative amino acid sequence of BaCHS contained active amino-acid residues that are highly conserved among all CHS sequences, 
and $\mathrm{BaCHS}$ is a homolog of the CHS gene, with its protein being a typical CHS protein. The color changes of the Brunfelsia acuminata flower could be explained by several reasons. These may include the spatiotemporal regulation of anthocyanin biosynthetic genes and/or their regulatory genes, or mutational effects on the structural genes encoding enzymes for anthocyanin biosynthesis. Simultaneously, the expression levels of CHS and the external factors are closely related, such as light, temperature, water and so on. For example, light is the key environmental factor, without light, it will hinder the synthesis of anthocyanins in flower petals and inhibit the expression of CHS gene, eventually leading to corolla coloring [19]. The stronger the light, the more anthocyanins accumulate. Blue light and ultraviolet light are the most effective light qualities for the synthesis of anthocyanin [20]. Temperature is too high or too low, the stability of anthocyanins will be affected [21]. However, we focused on the first possibility because purple petal pigmentation decreased dramatically with the petal development (Figure 1). To determine the expression patterns of three anthocyanin biosynthetic genes in petal in detail, quantitative RT-PCR was performed using total RNA isolated from bud and petals. CHS controls the first step in anthocyanin biosynthesis. Thus, we assume that its expression is high in the petal of the Brunfelsia acuminata flower. It has been documented that CHS is correlated with anthocyanin synthesis in Malus [22], Morus alba [14], Vitis vinifera [23,24], Pyrus [25], and Fragaria ananassa [26-28].

As expected, $\mathrm{CHS}$ transcript levels increased to a maximum in Day 1 flowers that were beginning to change color and thereafter decreased as petal coloration continued to develop. The abundance of CHS mRNA increased more than 2-fold between Days 0 and 1 before decreasing to the lowest level by Day 5 (Figure 6). RT-qPCR analysis demonstrated that the pattern of $C H S$ gene expression in Brunfelsia acuminata was positively correlated with the contents of anthocyanin $(p \leq 0.01)$. Therefore, the results suggested that the color of the petal was attributed to a high expression of CHS. The expression decreased significantly from Day 3 to Day 5, and the anthocyanin content dropped sharply. Thus, the petal color disappeared on the 5 th day of flowering. Anthocyanin degradation and lower level expression of CHS gene for the enzyme involved in anthocyanin synthesis appeared to end by Day 5, indicating that the bud and initial flowering stages (Day 0-1) represent the key phase of anthocyanin biosynthesis and that the degradation of anthocyanin started on Day 2. Our results also indicated that $\mathrm{BaCHS}$ expression and total anthocyanin accumulation in different tissues clearly showed the different patterns. Modulation of the Brunfelsia acuminata CHS gene may advance genetic engineering of flower color.

In addition, it's worth noting that the chalcone isomerase (CHI) catalyzing the next step was previously identified in B. acuminate [16]. Both CHS and CHI are key enzymes in anthocyanin biosynthesis. CHS catalyzes the first step of the reaction, and the $\mathrm{CHI}$ catalyzes the second reaction. Their changes in expression of level or loss of function and inactivation of the enzyme will directly affect the levels of flavonol compounds [29]. The protein accumulation of CHS and CHI are coordinately. This effect is due to the coordinative expression of CHI and CHS mRNA [30]. The comparison of the expression of these two genes during flower maturation will be done in the future.

\section{Materials and Methods}

The Brunfelsia acuminata was grown in the campus of Fujian Agriculture and Forestry University. Flower buds opened with dark purple petals that changed to purple and then to light purple and then to white as the flower aged during a 6-day lifespan. Flower developmental stages were divided into bud stage as Day 0 and flower open as Day 1 and the flower color fading away as Day 5. Flowers were tagged based on stages. The tagged flowers at different developmental stages were then harvested daily for experimental evaluation of petal coloration and gene expression. All samples were immediately frozen in liquid nitrogen and stored at $-80{ }^{\circ} \mathrm{C}$ until use. Primers used in the study of $\mathrm{BaCHS}$ are shown in Table 1. 
Table 1. Primers used in the study of BaCHS and RT-qPCR.

\begin{tabular}{|c|c|c|}
\hline Primer & Primer Sequence & Use \\
\hline CHS-conF(forward) & 5'-GAGAARTTCMRGCGCATGTGYG-3' & cDNA \\
\hline CHS-conR(reverse) & $5^{\prime}$-GCTTGGTGAGYTGRTAGTCRG-3' & \\
\hline GSP1(forward) & 5'-CGGCGCATGTGTGATAAATCA-3' & 3'RACE-PCR \\
\hline GSP2(forward) & 5'-GGTACATGCACTTAACAGAGG-3' & \\
\hline UPM & 5'-CTAATACGACTCACTATAGGGCAAGCAGTGGTATCAACGCAGAGT-3' & \\
\hline GSP3(reverse) & $5^{\prime}$-TCACAAATCTTGGGGTTCTC-3' & 5'RACE-PCR \\
\hline GSP4(reverse) & 5'-CTAGCATCAAGGGAAGGAGCC-3' & \\
\hline UPM & 5'-CTAATACGACTCACTATAGGGCAAGCAGTGGTATCAACGCAGAGT-3' & \\
\hline $\mathrm{FPF}$ (forward) & 5'-ATGGTGACCGTAGAGGAGTATCG-3' & Full-length \\
\hline FPR (reverse) & $5^{\prime}$-GAACCCACTAAGTAGCCACACTG-3' & \\
\hline CHS-F(forward) & 5'-CAAAGGAGGGCTTAGGAACTACT-3' & RT-qPCR \\
\hline CHS-R(reverse) & 5'-CAAATTCAACCCCAAGAACAAATGA-3' & \\
\hline BaActin- $\mathrm{F}$ (forward) & 5'-AACCATAAACGATNCCGACCAG-3' & \\
\hline BaActin-R(reverse) & 5'-NCTTGCGACCATACTCCC-3' & \\
\hline
\end{tabular}

Total anthocyanin contents were determined according to the method of Weiss and Halevy [31] with slight modifications. In brief, $0.2 \mathrm{~g}$ of each tissue was ground in liquid nitrogen and total anthocyanins were extracted with $\mathrm{HCl} /$ ethanol $(1: 99, v / v)$ at $60{ }^{\circ} \mathrm{C}$ for $4 \mathrm{~h}$. The samples were centrifuged at 12,000 rpm for $20 \mathrm{~min}$. The supernatants were retained and the absorbance values were determined using UV spectrophotometry at $535 \mathrm{~nm}$ and $650 \mathrm{~nm}$. The anthocyanin content was measured in milligrams per gram fresh weight tissue [32].

Genomic DNA was extracted from the leaves of Brunfelsia acuminata using DNA extraction kits and following the manufacturer's instructions (Biospin, Beijing, China), and total RNA was extracted separately from petals at different developmental stages by using RNA extraction kits (BioTeke, Beijing, China) [16]. The quality and concentration of the RNA and DNA were determined by agarose gel electrophoresis and spectrophotometer analysis. To amplify the conserved fragments of $\mathrm{BaCHS}$, degenerate oligonucleotide primers were designed based on conserved amino acid regions of other plant species obtained from the GenBank database using NCBI BLAST. RT-PCR was performed using the RevertAidTM First-Strand cDNA Synthesis Kit (Fermentas, Shanghai, China). The PCR product was purified and cloned into the pMD18-T vector (Takara, Dalian, China), and then sequenced at Biosun Company (Shanghai, China). Subsequent BLAST results confirmed that the amplified product was a partial fragment of the BaCHS gene. The $3^{\prime}$ end and $5^{\prime}$ end sequences were amplified using Super SMARTerTM RACE cDNA Amplification Kits (Clontech, Mountain View, CA, USA), and the open reading frame (ORF) was amplified by RT-PCR. The primers for $3^{\prime}-\mathrm{RACE}$ and $5^{\prime}$-RACE were designed to the originally conserved region, and the ORF primers were designed by cDNA assembly with the conserved region, $3^{\prime}$ end sequence and $5^{\prime}$ end sequence. PCR amplified products were examined on a $1.0 \%$ agarose gel by electrophoresis. Then, the products were cloned into the pMD-18T vector (Takara, Dalian, China) and sent for sequencing at the Biosun Company. After comparing and aligning the sequences of the $5^{\prime}$-RACE, $3^{\prime}$-RACE, and the internal region products, the full-length cDNA sequence of $B a C H S$ was obtained through RT-PCR. The PCR product was purified and cloned into the pMD18-T vector followed by sequencing. Subsequently, the full-length cDNA of $B a C H S$ was analyzed for molecular characterization.

For quantitative reverse-transcription PCR (RT-qPCR), the cDNA was synthesized using the PrimeScript ${ }^{\circledR}$ RT Reagent Kit according to the manufacturer's instructions (Takara, Dalian, China), and transcripts were amplified with an SYBR Premix ExTaqTM II kit (Takara, Dalian, China). The relative gene expression was calculated using the $2^{-\triangle \triangle \mathrm{Ct}}$ method [33]. RT-qPCR experiments were performed in triplicate. The BaActin gene from Brunfelsia acuminata was used as an internal reference as shown in Table 1.

The data determined in triplicate were analyzed by analysis of variance (ANOVA) using SPSS version 16.0 (IBM, Armonk, NY, USA)). The significance of differences was determined according to Duncan's multiple range test (DMRT). $p$ values $\leq 0.05$ are considered to be significant. The results are presented as the means \pm SD. Pearson correlation was calculated by SPSS version 16.0 with 2-tailed test of significance. 
Supplementary Materials: Supplementary materials can be accessed at: http://www.mdpi.com/1420-3049/22/ $1 / 44 /$ s1.

Acknowledgments: This work was supported by the National Training Programs of Innovation and Entrepreneurship for Undergraduates of China (Award No. 201510389020).

Author Contributions: Min Li performed the experiments (RT-qPCR and anthocyanin determination) and wrote paper. Yu-Ting Cao performed the experiments (isolation of $\mathrm{BaCHS}$ ) and wrote paper. Si-Rui Ye collected and analysed the data. Teng-Fei Pan and Muhammad Irshad provided the materials and reagents. Dong-Liang Qiu conceived, designed the study and wrote paper.

Conflicts of Interest: The authors declare no conflict of interest.

\section{References}

1. Claudot, A.C.; Ernst D, H.S., Jr.; Drouet, A. Cloning and characterization of two members of the chalcone synthase gene family from walnut. Plant Physiol. Biochem. 1999, 37, 721-730. [CrossRef]

2. Schmelzer, E.; Jahnen, W.; Hahlbrock, K. In situ localization of light-induced chalcone synthase mRNA, chalcone synthase, and flavonoid end products in epidermal cells of parsley leaves. Proc. Nat. Acad. Sci. USA 1988, 85, 2989-2993. [CrossRef] [PubMed]

3. Schulze-Lefert, P.; Becker-Andre, M.; Schulz, W. Functional architecture of the light-responsive chalcone synthase promoter from parsley. Plant Cell 1989, 1, 707-714. [CrossRef] [PubMed]

4. Holton, T.A.; Cornish, E.C. Genetics and biochemistry of anthocyanin biosynthesis. Plant Cell 1995, 7, 1071-1083. [CrossRef] [PubMed]

5. Franken, P.; Niesbach-Klosgen, U.; Weydemann, U.; Marechal-Drouard, L.; Heinz, S.; Wienand, U. The duplicated chalcone synthase genes C2 and Whp. (white pollen) of Zea mays are independently regulated; evidence for translational control of Whp. expression by the anthocyanin intensifying gene. EMBO J. 1991, 10, 2605-2612. [PubMed]

6. Saslowsky, D.E.; Dana, C.D.; Winkel-Shirley, B. An allelic series for the chalcone synthase locus in Arabidopsis. Gene 2000, 255, 127-138. [CrossRef]

7. Sommer, H.; Saedler, H. Structure of the chalcone synthase gene of Antirrhinum majus. Mol. Gen. Genet. 1986, 202, 429-434. [CrossRef]

8. Helariutta, Y.; Kotilainen, M.; Elomaa, P. Duplication and functional divergence in the chalcone synthase gene family of Asteraceae: Evolution with substrate change and catalytic simplification. Proc. Nat. Acad. Sci. USA 1996, 3, 9033-9038. [CrossRef]

9. Sparvoli, F.; Martin, C.; Scienza, A.; Gavazzi, G.; Tonelli, C. Cloning and molecular analysis of structural genes involved in flavonoid and stilbene biosynthesis in grape (Vitis. vinifera L.). Plant Mol. Biol. 1994, 24, 743-755. [CrossRef] [PubMed]

10. Yuan, Y.; Ma, X.H.; Shi, Y.M.; Tang, D.Q. Isolation and expression analysis of six putative structural genes involved in anthocyanin biosynthesis in Tulipa fosteriana. Sci. Hort. 2013, 153, 93-102. [CrossRef]

11. Koes, R.E.; Spelt, C.E.; Mol, J.N.M. The chalcone synthase multigene family of Petunia hybrid (V30): Differential, light-regulated expression during flower development and UV light induction. Plant Mol. Biol. 1989, 12, 213-225. [CrossRef] [PubMed]

12. Durbin, M.L.; McCaig, B.; Clegg, M.T. Molecular evolution of the chalcone synthase multigene family in the morning glory genome. Plant Mol. Biol. 2000, 42, 79-92. [CrossRef] [PubMed]

13. Elomaa, P.; Honkanen, J.; Puska, R.; Seppanen, P.; Helariutta, Y.; Mehto, M.; Kotilainen, M.; Nevalainen, L.; Teeri, T.H. Agrobacterium-mediated transfer of antisense chalcone synthase cDNA to Gerbera hybrida inhibits flower pigmentation. Biotechnology 1993, 11, 508-511. [CrossRef]

14. Li, J.; Lü, R.H.; Zhao, A.C.; Wang, X.L.; Liu, C.Y.; Zhang, Q.Y.; Wang, X.H.; Umuhoza, D.; Jin, X.Y.; Lu, C.; et al. Isolation and expression analysis of anthocyanin biosynthetic genes in Morus. alba L. Biol. Plant 2014, 58, 618-626. [CrossRef]

15. Grotewold, E. The genetics and biochemistry of floral pigments. Annu. Rev. Plant Biol. 2006, 57, 761-780. [CrossRef] [PubMed]

16. Cao, Y.T.; Qiu, D.L. Cloning and sequence analysis of chalcone isomerase Gene (CHI) from Brunfelsia acuminata flowers. J. Trop. Subtrop. Bot. 2012, 20, 475-481. 
17. Zipor, G.; Duarte, P.; Carqueijeiro, I.; Shahar, L.; Ovadia, R.; Teper-Bamnolker, P.; Eshel, D.; Levin, Y.; Doron-Faigenboim, A.; Sottomayor, M.; et al. In planta anthocyanin degradation by a vacuolar class III peroxidase in Brunfelsia calycina flowers. New Phytol. 2015, 205, 653-665. [CrossRef] [PubMed]

18. Vaknin, H.; Bar-Akiva, A.; Ovadia, R.; Nissim-Levi, A.; Forer, I.; Weiss, D.; Oren-Shamir, M. Active anthocyanin degradation in Brunfelsia calycina (yesterday-today-tomorrow) flowers. Planta 2005, 222, 19-26. [CrossRef] [PubMed]

19. Luo, J.J.; Li, H.; Bai, B.B.; Yu, H.Q.; You, J. Effect of Light on the Anthocyanin Biosythesis and Expression of CHS and DFR in Rosa chinensis 'Spectra'. Mol. Plant Breed. 2013, 11, 126-131.

20. Ohto, M.; Onai, K.; Furukawa, Y.; Aoki, E.; Araki, T.; Nakamura, K. Effects of sugar on vegetative development and floral transition in Arabidopsis. Plant Physiol. 2001, 127, 252-261. [CrossRef] [PubMed]

21. Wang, J.; Zhao, M.Z.; Hong-Mei, Y.U. Semilethal Temperatures for Flowers of Two Strawberry Varieties under Low Temperature Stress. Jiangxi Nongye Daxue Xuebao 2012, 34, 255-258.

22. Tian, J.; Shen, H.X.; Zhang, J.; Song, T.T.; Yao, Y.C. Characteristics of chalcone synthase promoters from different leaf-color malus crabapple cultivars. Sci. Hort. 2011, 129, 449-453. [CrossRef]

23. Azuma, A.; Ban, Y.; Sato, A.; Kono, A.; Shiraishi, M.; Yakushiji, H.; Kobayashi, S. MYB diplotypes at the color locus affect the ratios of tri/di-hydroxylated and methylated non-methylated anthocyanins in grape berry skin. Tree Genet. Genoms 2015, 11,1-13. [CrossRef]

24. González, C.V.; Fanzone, M.L.; Cortés, L.E.; Bottini, R.; Lijavetzky, D.C.; Ballaré, C.L.; Boccalandro, H.E. Fruit-localized photoreceptors increase phenolic compounds in berry skins of field-grown Vitis. vinifera L. cv. Malbec. Phytochemistry 2015, 110, 46-57. [CrossRef] [PubMed]

25. Yang, Y.N.; Yao, G.F.; Zheng, D.M.; Zhang, S.L.; Wang, C.; Zhang, M.Y.; Wu, J. Expression differences of anthocyanin biosynthesis genes reveal regulation patterns for red pear coloration. Plant Cell Rep. 2015, 34, 189-198. [CrossRef] [PubMed]

26. Kayesh, E.; Shangguan, L.F.; Korir, N.K.; Sun, X.; Bilkish, N.; Zhang, Y.P.; Han, J.; Song, C.N.; Cheng, Z.M.; Fang, J.G. Fruit skin color and the role of anthocyanin. Acta Physiol. Plant 2013, 35, 2879-2890. [CrossRef]

27. Ju, Z.G.; Liu, C.L.; Yuan, Y.B. Activities of chalcone synthase and UDPGal: Xavonoid-3-O-glycosyltransferase in relation to anthocyanin synthesis in apple. Sci. Hort. 1995, 63, 175-185. [CrossRef]

28. Mori, T.; Sakurai, M.; Sakuta, M. Effects of conditioned medium on activities of PAL, CHS, DAHP synthase (DS-Co and DS-Mn) and anthocyanin production in suspension cultures of Fragaria ananassa. Plant Sci. 2001, 160, 355-360. [CrossRef]

29. Muir, S.R.; Collins, G.J.; Robinson, S.; Hughes, S.; Bovy, A.; Vos, C.H.R.D.; Tunen, A.J.; Martine, E.; Verhoeyen, M.E. Over expression of petunia chalcone isomerase in tomato results in fruit containing increased levels of flavonols. Nat. Bioteehnol. 2001, 19, 470-474. [CrossRef] [PubMed]

30. Tunen, A.J.V.; Koes, R.E.; Mol, J.N.M. Coning of the two chalcone flavanone isomerase genes form Petunia hybrid co-ordinate, light-regulated and differential expression of flavonoid genes. EMBO J. 1988, 7, 1257-1263. [PubMed]

31. Weiss, D.; Halevy, A.H. Stamens and gibberellin in the regulation of corolla pigmentation and growth in Petunia hybrida. Planta 1989, 179, 89-96. [CrossRef] [PubMed]

32. Yang, G.C.; Chen, X.Y.; Wang, J.; Du, C.; Zhang, K.; Cai, Y.M.; Gao, X.; Tang, D.B.; Zhao, Y. Anthocyanin extraction from purple sweet potato by citric acid-disodium hydrogen phosphate buffer. J. South. Agric. 2013, 44, 653-656.

33. Bar-Akiva, A.; Ovadia, R.; Rogachev, I.; Bar-Or, C.; Bar, E.; Freiman, Z.; Nissim-Levi, A.; Gollop, N.; Lewinsohn, E.; Aharoni, A. Metabolic networking in Brunfelsia calycina petals after flower opening. J. Exp. Bot. 2010, 61, 1393-1403. [CrossRef] [PubMed]

Sample Availability: Samples of the compounds are available from the authors.

(C) 2016 by the authors; licensee MDPI, Basel, Switzerland. This article is an open access article distributed under the terms and conditions of the Creative Commons Attribution (CC-BY) license (http:/ / creativecommons.org/licenses/by/4.0/). 